\title{
LA TRADICIÓN CLÁSICA CASTELLANA Y SUS VALORES UNIVERSALES EN LA VOZ A TI DEBIDA
}

\author{
EdUARDo Madrid CoBos \\ rigelemc@hotmail.com
}

\section{RESUMEN}

Este artículo pretende mostrar una serie de temas presentes en la trilogía central de Pedro Salinas (1891-1951), mayormente en La voz a ti debida (1933), de arraigo en la tradición clásica castellana (medieval y renacentista), pero también en sus Cartas a Katherine Whitmore (1932-1947). Se incide en la importancia de la tradición literaria española para Salinas y su resonancia en la moralidad universal, de acuerdo con Juan Marichal en su ensayo «Pedro Salinas y los valores humanos de la literatura hispánica».

Palabras Clave: Pedro Salinas, tradición clásica castellana, universalidad, amor, cartas.

\section{ABSTRACT}

This article attempts to reveal a series of subjects present at Pedro Salinas' (1891-1951) main trilogy, mostly at La voz a ti debida (1933), rooted in the Castilian classic tradition (medieval and Renaissance), but also in his Cartas a Katherine Whitmore (1932-1947). Significance of Spanish literary tradition for Salinas and repercussions in universal morality are highlighted, according to Juan Marichal essay's «Pedro Salinas y los valores humanos de la literatura hispánica».

KEYwords: Pedro Salinas, Castilian classic tradition, universality, love, letters. 


\section{LA TRADICIÓN PARA PEDRO SALINAS}

Pedro Salinas, como crítico y ensayista además de poeta, señalaba que al seguir corrientes literarias muy representativas de nuestra tradición existía siempre un tema vital, como indica Marichal (1976: 259). Hemos procurado rastrear el significado de ese tema vital en la poesía amorosa de Salinas desde el concepto de tradición y los valores humanos universales que se desprenden de ella.

Como subraya el propio Salinas, es esencial la simbiosis entre tradición y originalidad en toda obra poética relevante. De este modo, «para comprender a un poeta hay que tratar de encontrar su tema vital y ver cómo se combinan la tradición y la originalidad para configurar este tema [...]» (Ciplijauskaité, 1991: 91). Éstas dos vertientes son confluyentes e inestimables la una con la otra.

Una de las razones mayores para afirmarlo era que, como experto poeta y crítico, sabía muy bien la significancia de la tradición en la literatura hispánica, puesto que era lo que explicaba la particular «moralidad española», que a su vez era universal: «Para Salinas la literatura española era universal en su condición misma puesto que expresaba ante todo los valores humanos de la España moderna» (Marichal, 2002: 214). En EE. UU., ya consagrado como poeta y profesor universitario (bien sabido es que la generación del 27 era característica por «poetas-profesores», como decía Juan Ramón), Salinas adquiere el conocimiento de la crítica angloamericana y con ella evoluciona, lo que supone la «fortuna» dentro de lo doloroso de su exilio, como opina Marichal. Esta modernidad se deja ver en su obra Jorge Manrique o tradición y originalidad (1947) que, como dice Ciplijauskaité, junto con La poesía de Rubén Darío (1948), muestran cómo comprender a un poeta mediante su tema vital. Estas dos obras tan personales de Salinas acerca de poetas emblemáticos en el tema del amor, en el que él mismo se erigió como uno de los mejores de todos los tiempos, destilan sus propias claves de creación poética sustentadas por la tradición, y la importancia que le daba a ésta. Como dice Jorge Guillén (1967: 140), «Sin el sentido histórico no se ve la obra, ni siquiera de modo inmediato. No existe actualidad sin historia ni hay valor histórico sin vínculos con los valores actuales, de suerte que funcionan juntos el interés por la literatura del pasado y la participación en la literatura contemporánea».

Esta idea es la causante de que Salinas dedique un vasto y bellísimo pasaje al concepto de «tradición» en su libro sobre Manrique. Lo primero que hace es denostar los términos como influencias, precursores o fuentes, a favor de la «tradición», de mayor complejidad, mediante un símil biológico: «En historia natural se denomina hábitat, habitación, la zona donde se cría adecuadamente una cierta especie vegetal o animal. En historia espiritual la tradición es la habitación natural del poeta» (Salinas, 1970: 115).

En efecto, el que vive en un lugar vive sobre profundidades: «¿Qué sabe la moza que recolecta la aceituna en un olivar de Andalucía de la copla que canta?», dice Salinas (1970: 117). En efecto, tal copla puede tener algo de una compilación medieval recogida por eruditos de cantos populares, puede tener algo de poesía culta, o puede ser hasta un «desgaje de un soneto de Petrarca». La muchacha es por tanto «agente inconsciente y purísima de una gran fuerza», la tradición. Esto sucede porque quien lleva la tradición está íntimamente relacionada con el lenguaje, que es el medio por el cual ésta fluye (traditio significa «acción de 
dar a través de una serie de mediadores», Cristóbal, 2005: 29): «en él recibe el hombre una masa de concreciones tradicionales de pensamiento y sentimiento» (1970: 118). Por tanto, aunque alguien sea analfabeto, su propio lenguaje le hace nutrirse de todo ese pensamiento de generaciones anteriores, quizá incluso de manera más «pura» que las élites cultas. «Con tan poco saber, el analfabeto sabe lo que hay que hacer», dice Salinas (1970: 118). Escartín ya ha destacado esta postura apologética de Salinas, como gran defensor de los knoi topoi que, transmitidos desde la Antigüedad y reasentados en la Edad Media, han perdurado hasta hoy dando a la literatura europea una unidad de sentido (Escartín, 1993: 135).

Mientras que se ha de admitir que los poemas van «de la voz a la memoria, de la memoria a la voz» (1970: 121), muchos intelectuales ven, por el contrario, que la tradición es un obstáculo para la iniciativa del artista. Todo lo contrario: en ella el escritor se encuentra en libertad plena, pues en el vacío no hay libertad alguna. Cuanto mayor sea la capacidad de elección, más intensa será la conciencia de poder del artista, más vastos serán sus dominios. En este análisis de la tradición de la que se nutrió Manrique se funda el principio de creación poética del propio Salinas, como fácilmente nos da a entender aquí (1970: 124):

Cuando el escritor de hoy se ve superior al de la Edad Media o al del siglo XVIII, el único fundamento para esta creencia está en que tiene en torno suyo más pasado literario, más tradición. [...] El explorador, el artista de hoy se halla con más caminos abiertos que nunca: son los trazados por sus antecesores. [...] saber por dónde anduvieron los demás le enseña a uno a saber por dónde se anda.

Esta manera de Salinas de concebir y defender la tradición como principio fundamental de creación poética le lleva a escribir su propia poesía bajo esta pauta, porque la poesía no es, como dice la cita que incluye de Gilbert Murray, una competición en que cada uno afirma su individualidad y procura dejar a los anteriores poetas obsoletos, sino un «culto común donde todos los sirvientes de las Musas se afanan en un servicio común, ayudándose todos» (apud Salinas 1970: 126-127). Solamente, tras toda esta inspiración, hay un momento de soledad del artista en que debe apartarse de todos y avanzar solo.

Nótese que el movimiento literario de la generación del 27 tiene lugar tras las vanguardias cuyo estandarte era siempre la ruptura con toda tradición anterior. Poco después de la Primera Guerra Mundial, los jóvenes que se autotitularon vanguardistas regresaron a la tradición, reafirmándola y dándole vida bajo la innovación y la originalidad, pero sin jamás despreciar aquélla. El propio Lorca, como uno de los mayores responsables de las Misiones Pedagógicas, postulaba que lo primero que se ha de respetar y potenciar en cada pueblo es la tradición. Por otra parte, no hay que olvidar que el propio nombre de la generación o grupo del 27 se debe a la conmemoración del tercer centenario de la muerte de Góngora, con lo que la tradición aurisecular se revitalizó y actualizó hasta el punto de llegar a llamarse esta época «Edad de Plata» de la literatura española. Se logró el buscado equilibrio entre arte popular y minoritario, «poesía pura» y comprometida, innovación y disciplina, tradición y renovación.

Pedro Salinas, como uno de los principales artífices de toda esta síntesis, recoge la tradición muy conscientemente, por ser amante declarado de la literatura española. En el siguiente apartado se rastrearán los diversos aspectos tradicionales castellanos en la famosa trilogía de su etapa central, centrándonos en La voz a ti debida. 


\section{ASPECTOS TRADICIONALES CASTELLANOS EN LA VOZ A TI DEBIDA Y RAZÓN DE AMOR}

Biruté Ciplijauskaité llama a Salinas «siervo de amor» (1991: 91) y a su vez el propio poeta siente predilección por Jorge Manrique. Será este poeta medieval uno de los referentes fundamentales a los que hace honor Salinas, no solamente en lo que se refiere a tradición literaria, al ser poesía que se sirvió de la obra anterior y contribuyó a la posterior, sino en lo que supone el espíritu de amor cortés arraigado en la cultura universal que, si bien esta corriente cultural tuvo origen provenzal, también dio frutos en la literatura española, hasta llegar a encarnarla Salinas tanto en vida como en obra.

El amor cortés provenzal, telón de fondo de la poesía cancioneril castellana del siglo XV, era una forma de ver y entender la vida en la sociedad cortesana medieval. C. S. Lewis (2000: 12) señaló cuatro características: humildad (postura servil ante la dama), cortesía (conjunto de cualidades y virtudes, y en su aspecto social, el elitismo), adulterio (amor y matrimonio son antagónicos) y religión de amor (mujer como objeto de culto, amor como fuente de bondad). Salinas recuerda además este estado de amante fijado en la literatura: el amante se complace en su propio ser así, elevado a un plano superior de existencia, desligado de todo interés material. «Porque lo que se crea es la ficción de una situación psicológica donde la inquietud, el desasosiego se estabilizan, y pasan, de excepcionales, a normales» (Salinas, 1970: 13). No hay un fin en amar porque amar es un fin en sí $^{1}$. El objetivo es siempre no alcanzar, sino seguir sirviendo, seguir anhelando (Salinas, 1970: 30). El hecho de no alcanzar es fundamental, y es el principal paralelismo entre Jorge Manrique, como heredero castellano del amor cortés, y Pedro Salinas, que mantiene tal actitud, actualizada pero igual en esencia, en pleno siglo XX.

Pueden entonces encontrarse, en cierto modo, las cuatro características del amor cortés en Salinas. La humildad es constante en cuanto a la servidumbre, a estar siempre a merced de los deseos de la dama, de su presencia o ausencia, de su atención o desdén («Afán / por no separarme / de ti, de tu belleza», 831-8332; «Yo no puedo darte más. / No soy más que lo que soy», 857-858; «Miedo. De ti. Quererte / en el más alto riesgo», 164-165; «Pero de pronto tú / dijiste: «Yo, mañana...», 208-209; «iSi me llamaras, sí, / si me llamaras!», 102103). De esta humilitas se desprende, como parte de esa inferioridad, la carga del dolor, que Jorge Manrique y otros poetas de Cancionero expresaron con un amplio corpus de campos semánticos: dolor, herir, llagas, sufrimiento... Escartín (1993: 138) anota que en esta casuística trovadoresca, cuya estela sigue Salinas, el poeta no desea evitar el dolor, sino que además lo alimenta: «No quiero que te vayas, / dolor, última forma / de amar. Me estoy sintiendo / vivir cuando me dueles» (2191-2194). Este dolor, además, suele ser también producto de una lucha, por la resistencia o negativa femenina, que se suele manifestar también como lucha del amante consigo mismo. Así decía Manrique «no tener guerra conmigo» con la venida de la

${ }^{1}$ El afianzamiento psicológico de la acción de amar en el estado de amante que describe Salinas, sin otro fin más allá, lo concreta Katz Krispín (1998: 663) con esta idea: «[...] el amante desea un beso, pero el poeta desea simplemente desearlo».

2 Siempre que no se indique la obra a la que pertenecen los versos, se tratará de La voz a ti debida. 
muerte. Escartín (1993: 139) relaciona el tópico del amor como lucha con los versos 10481051 y 1054-1057 de Razón de amor.

La cortesía tiene, naturalmente, la parte de estamento social inaplicable en el siglo XX, pero sí procede lo referente a virtudes, «forma del intelecto, doctrina de existencia, estilización de conductas sentimentales» (Salinas, 1970: 26). La consagración al amor del poeta/ amante supone esta transmutación a un plano superior ${ }^{3}$ mediante esa doctrina, esas conductas. El amor es «cortés» porque «a fuerza de exigirse a sí mismo virtudes, abnegaciones y esfuerzos, puede mirarse como una escuela de conducta moral» (1970: 26). No es raro que en este progreso moral del enamorado se pueda, como un filósofo, ver lo divino (ta theia orao, «teoría» ${ }^{4}$ ), transcender («ir más allá», «comprender lo oculto»): así Salinas siempre busca «detrás, más allá» (1970: 82), puede ver a la otra «tú» («Se te está viendo la otra», 1765). El amante ve mucho más que el cuerpo de la amada; ve el alma, indicada con ese pronombre (496-497), la verdadera tú, la sombra (1946).

La religión de amor, que puede adscribirse a lo que Salinas llama «gineolatría», supone una analogía al cristianismo en cuanto a estar religado (religión < religare) a un ser supremo, en este caso, la mujer, objeto de culto. Lo que era pecado para el cristianismo es aquí virtud, y en afianzar esta idea - la justificación moral y vital del erotismo - ya se encargó Rubén Darío en Prosas profanas. La devoción por la dama llega casi a lo obsesivo. Recuérdese a Calixto en La Celestina: «Melibeo soy...». Está este rasgo íntimamente relacionado con la humildad, pues existe igualmente una desproporción entre estados: el poeta amante, abajo; la dama amada (perfecta, inaccesible), en lo más alto. La divinización de ésta lleva a una sublimación de su materia corpórea, que, sin dejar de existir para Salinas («corporeidad mortal y rosa», 2461), está a punto de terminar en la donna angelicata, la amada de Dante, el conceptismo interior que propone Spitzer (1941: 39): «La amada es un concepto puro». Para algunos es inconcebible que sea la mujer tal concepto, como defienden González Muela, Jorge Guillén y otros, porque la mujer es real, existe (Escartín, 2016: 21; Feal Deibe, 2000: 39). Pero la propia Katherine Whitmore, el mejor testimonio que podamos tener, afirmaba que en gran medida la amada de Salinas en sus poemas no era ella: Enric Bou incluye en su fantástica edición de las Cartas el texto mecanografiado de Katherine en 1979, La amada de Pedro Salinas, que entregó junto a las 354 cartas y 144 poemas a la Houghton Library de la Universidad de Harvard. Allí se lee: «Es cierto que algunos poemas [...] pertenecen claramente a nuestro amor naciente, pero otros, sumamente apasionados, implican una experiencia que no conocimos» (Salinas, 2002: 381).

El adulterio es otro rasgo implícito en el amor cortés, rasgo que dolorosamente compartió Salinas en su enamoramiento, es decir, más allá de lo literario. La única diferencia con Manrique es que en la poesía medieval era la dama quien solía estar casada, o ambos; mientras que en la relación saliniana el casado es el autor. No obstante, como rasgo común y particular del

3 Salinas (1970: 23) describe en qué consiste la elevación de esta cortesía: «[...] servir al amor es un camino de perfección, aunque bien doloroso. Desinterés frente al egoísmo, paciencia frente al arrebato, obediencia frente a la soberbia, nobleza frente a traición».

${ }^{4}$ «To theion o ta theia orao significa «yo veo lo divino (theion)», «yo veo las cosas divinas (theia)». Y, en efecto, para los estoicos la theoria consiste en esforzarse por contemplar aquello que de «divino» tiene la realidad que nos rodea», Ferry (2007: 42). 
amor cortés castellano, no hay apenas referencias explícitas a este hecho en el texto, ni en la Edad Media ni en el siglo XX. En cualquier caso no cabe duda de que el amor está atado a la idea de libertad. El amor entre cónyuges no es posible, máxime cuando hasta finales del XIX e incluso bien entrado el XX los matrimonios eran concertados. El galardón que espera el amante suplicante sólo puede otorgarlo la dama en libertad, cuando el matrimonio es justo lo contrario: la esposa está sometida al marido. Que una dama casada reciba las atenciones de un verdadero amante es una transgresión, socialmente negativa, pero espiritualmente positiva, por el goce de la libertad tan anhelada (recuérdese, por ejemplo, a Ana Ozores con Álvaro Mesía en La regenta). Igual sucede si el casado es el hombre (La dama del perrito, Chéjov). Pero en ese goce hay una tensión, que es la certeza de que la realidad social no permite la consumación de ese amor. O no sólo la sociedad, sino el propio Salinas, que nunca consideró abandonar a su mujer, Margarita Bonmatí, ni mucho menos a sus hijos Solita y Jaime. Salinas, en una de sus cartas íntimas a Katherine, ya dando el amor por fracasado por haberse casado ésta, decía: «Es el tipo de amor fracasado en lo social, pero que se busca por dentro una compensación espiritual y proporciona una clase de felicidad intensa aunque no continua» (2002: 302). «Por consiguiente» —dice Salinas en otro lugar (1970: 30)—, «la poesía amatoria ha de permanecer en esa situación de suplicar, de adorar, de aspirar prolongarla todo lo posible, inventarle innumerables variantes porque conforme a la moral no puede pasar de ahí».

El adulterio, por tanto, es quizá el rasgo más importante que Salinas conserva del amor cortés, por la idea de prolongación, aun sabiendo (y repitiendo constantemente) que su amada lo abandonará: «Viví, vivo. ¿Hasta cuándo? / Sé que te volverás / atrás. Cuando te vayas / retornaré a ese sordo / mundo [...]» (2175-2179); «No quiero que te vayas, / dolor, última forma / de amar. [...]» (2191-2193); «¿Serás, amor, / un largo adiós que no se acaba?» (Razón de amor, 54-55). Esta idea que se desprende del adulterio enlaza con la aceptación gozosa de sufrimiento, general en el amor cortés, y todo el pensamiento filosófico en el que se incardina, pues el estado de amante plantea también existencialismo, con una salida en la búsqueda de la salvación: «salvación por la amada concreta, efímera; salvación por el amor en su esencia, más duradero; salvación por el poema, que transmite ya sólo la esencia depurada» (Ciplijauskaité, 1991: 96).

La elevación por el estado de amante la renueva Salinas para asumirla, más bien, como trasposición (detrás) o profundización («Amor total, quererse como masas», 1384). «La materia no pesa» (1585), luego el espíritu sí, porque está en lo profundo. No obstante, la aspiración de trascendencia y tentativa de asunción del mundo inmaterial mediante el amor coincide en valor absoluto con los tradicionales poetas místicos: San Juan de la Cruz y Santa Teresa de Jesús, quienes dejan su huella indeleble en la tradición clásica castellana. San Juan alude a la «separación del yo» en el acto amoroso, concepto clave en esta forma de trascendencia, en su famoso poema «Noche oscura del alma», con el decorado descrito con «aire», «viento», «almena», «cedros» y estados manifestados en «suspendía», «transformada», «quedéme y olvidéme». La misma idea la expresa Santa Teresa con sus conocidos versos: «Vivo sin vivir en mí, / y tan alta vida espero / que muero porque no muero». La «alta vida» esperada, que no

5 Como dice Juan Villegas, citando a Spitzer (Villegas, 1976: 129), al compararse a Salinas con San Juan de la Cruz, se deduce que en Salinas se trata «más bien de un cantar del alma que por falta de fe en Dios se afana por conocerse a sí misma». 
conseguida, es la misma que persigue Salinas en su actividad amatoria, rozándola sin llegar a conseguirla ${ }^{6}$, pero complaciéndose así («Cuando me abrazas, siento / que tuve contra el pecho / un palpitar sin tacto, / cerquísima [...]», 1603-1606). Es fundamental lo que dice Teresa: «fuera de mí», porque implica una distancia y una disolución del yo. La mención de la distancia es constante en Salinas: cuanto más lejos, menor posesión material, mayor conocimiento del amor recóndito, de las identidades que hay detrás: «Distánciamela, espejo», 1828; «Porque un día el beso tuyo, / de tan hondo / te va a nacer [...]», 1873-1875. «Vivo sin vivir en mí» implica vivir en el otro, y por tanto, morir, «muero porque no muero». Por eso Salinas insiste en los pronombres, que señalan, no nombran (nombrar es algo condicionado a la materia, a lo concreto), siempre en segunda persona, «tú», «te», «La voz a ti debida». Dirigirse al tú es automáticamente distanciarse del yo, fenómeno llamado por los filósofos alteridad, factor clave en el amor y en el erotismo ${ }^{7}$. Este uso intencionado de los pronombres, especialmente los de segunda persona, son un nexo existente entre Garcilaso y Salinas, como perfeccionamiento personal y poético a través del acto amoroso: en la vida real, la focalización en el otro bajo el impulso amoroso promueve el mencionado distanciamiento de uno mismo, incluso el desreconocimiento del yo, necesarios para una relación amorosa real, no el mero consumo de la persona concebida como objeto (Han, 2014: 24).

A colación de este dato sobre el sutil tratamiento desmaterializado del objeto amoroso, se ha mencionado polémicamente que la amada en la poesía saliniana no existe porque ha sido reducida a un concepto, lo cual también radica en la tradición literaria. El responsable de la gran difusión de esta idea, como es sabido, fue Leo Spitzer en 1941, aún en vida de Salinas, con su brillante artículo «El conceptismo interior de Pedro Salinas». Hay aseveraciones muy radicales: «[...] hasta la mujer amada es negada por nuestro poeta; no conozco poesía de amor donde la pareja amorosa se reduzca hasta tal punto al yo del poeta [...] este poeta no es sino un Narciso que no conoce a nadie que esté fuera de él» (1941: 37). Desde nuestro punto de vista, Spitzer ignoraba que, filosóficamente, el amor consiste precisamente en la referida dualidad de identidades separadas, donde la concepción de lo incorpóreo garantiza la plenitud del erotismo, la imposibilidad del consumo de la otra persona (Han, 2014: 9-10). Sin embargo, literariamente tiene gran parte de razón Spitzer, al justificarse en el propio texto y en la tradición petrarquista: «La mujer será tan puramente pasiva que ningún indicio de su amor pueda prestar materialidad a su persona, más tenue que la de Laura» (1941: 39). Para apoyar esta deducción, y señalar además de dónde la ha sacado Salinas, ofrece como prueba a Garcilaso: «mi alma os ha cortado a su medida, / por hábito del alma misma os quiero»; es decir, que el poeta, desde su alma, ha creado o inventado a la amada (o su imagen ideal), lo que establece incondicionalmente el estado de amante y la creación poética. Multitud de

${ }^{6}$ Se trata, en parte, de la innovación de Salinas en este aspecto. Villegas (1976: 137) comenta el poema «Qué alegría vivir / sintiéndose vivido» así: «El tema, en general, corresponde a la tradición de la poesía amorosa y, más específicamente, a la de la mística española. La necesidad de la «unio» como fin vital coincide con los anhelos unitivos más caros de los místicos. La diferencia radical, sin embargo, se encuentra en que [...] los místicos ambicionan ese anegamiento como fin en sí, y en el poema de Salinas, además de su valor descubridor del mundo, posee un sentido trascendente: persistir en el ser a través de la existencia de la amada» (cursiva mía).

7 Este hecho, presente ya en la tradición y recuperado por Salinas, revela su objetivo de universalización de la poesía, al hacer patentes los valores humanos de la literatura española. Véanse Conclusiones. 
críticos $^{8}$ se mostrarán en contra de esta conclusión: «¿Y cómo nacería ese pensamiento sin la dulzura de ese cuerpo?» (Guillén, 1967: 147).

Así, según Spitzer, hay un puente que une directamente el conceptismo9 , el juego intelectual como fin en sí, entre el Barroco y Salinas. Poeta y lector se complacen en el propio intelecto, más allá de la posible realidad, porque lo que realmente importa es lo pensado. «Tu solo cuerpo posible: / tu dulce cuerpo pensado» (1980-1981). Spitzer hace una ingeniosa comparación con el famoso poeta amigo del Greco: «Yo pongo al lado del soneto de Paravicino los versos siguientes de Salinas: 'duda' ante un Doppelgänger, ante un ménéchme que es, en sí, la Amada y que se expresa en la forma del concepto [...]; mis actos que ella hace es una paradoja realizable solamente por intelecto» (1941: 64). Esto es el conceptismo interior de Salinas y la huella de la tradición del Siglo de Oro en su poesía.

El conceptismo y el Barroco se manifiestan también bajo la figura de Quevedo, en cuyo famoso soneto Amor más allá de la muerte se da de manera tan bellamente hiperbólica el estado de amante. Seguir amando a pesar de estar muerto (muerte real, en este caso) guarda cierta relación con el hecho de amar desde lo incorpóreo. Tanto Quevedo como Salinas otorgan un papel fundamental a la palabra «sombra» («la postrera sombra» [Quevedo] - «volverse sombra» [Salinas]). Katz Krispín (1998: 663) relaciona, además, los versos 2317-2318 con «la imagen quevedesca de la vida que se escapa de las manos [«Cómo de entre mis manos te resbalas»], trocando el tema de vida y muerte en amor y pérdida, pero aclarando que ni la imagen ni la idea de la ausencia es amenazadora». La evocación temática de Quevedo será más fuerte en Largo lamento, enlazándose en los temas predilectos de Salinas: el recuerdo y la ausencia de la amada. Es significativo, pues, como refugio del poeta en la memoria, Miré los muros de la patria mía. Lo más importante en el poeta amante es no sucumbir nunca al olvido, como sucede en «Si hija de mi amor mi muerte fuese» de Quevedo: «Es la pasión de su amor que causa su propia muerte [=«morir en el otro», alteridad], y da a luz a la memoria de la belleza de la amada. La muerte del amante, si seguimos la lógica del soneto, será la hija de su amor; la pasión de este amor hará que, al morirse el amante, la belleza de la amada derrote el olvido; el no-ser del amante será, así, a causa de su amor, su gloria» (Katz Krispín, 1998: 665). Escartín (1993: 140-141) destaca una innovación saliniana en el tópico de la pervivencia del amor más allá de la muerte: «este fuego en el que se consume el amante [...] no sobrevive a un cuerpo consumido, «es» pura corporeidad que el yo poético encuentra

[...] su cuerpo, el del amor, [...]

que inútilmente esperarán las tumbas.»

\footnotetext{
${ }^{8}$ Muchos están en contra de la aseveración de Spitzer de que la amada «no existe». Guillén (1967: 147): «¡Conclusión monstruosa! Esta vez [...] el gran Spitzer se equivocó [...]». Debicki (1976: 122): «Este «tú» no es ni más ni menos que una mujer, de carne y hueso, que, como toda criatura carnal, está determinada y limitada por el tiempo y el espacio. «El tierno cuerpo rosado», «la arena» y el «reló» son las representaciones inequívocas de estos tres aspectos centrales de la condición humana». También González Muela (1974), como se lee en la nota siguiente.

${ }^{9}$ González Muela (1974: 35) justifica que tampoco se puede llamar «conceptista» a Salinas, tras un elaborado desarrollo en el prólogo de la edición en Castalia: «A un poeta para el que el hondo significado es lo más importante no se le puede llamar «conceptista». Hemos visto sufrir a Salinas con las palabras, no jugar con las palabras, que es lo que «conceptismo» significa».
} 
El amor puede entenderse, en lo clásico y en Salinas, como vía de salvación. Como bien dice Ciplijauskaité (1991: 96), citando a Salinas, que así pensaba tanto de Manrique como de su propia poesía: «¿qué le queda al poeta despojado de Dios, de su dama y de él mismo? Al poeta le queda el quedarse con el amor». Y de este modo se consolaba también Quevedo ante sus restos mortales: «polvo serán, más polvo enamorado».

No obstante, es en la línea establecida por Petrarca y por Garcilaso donde mejor se sitúa a Salinas en cuanto a la tradición, que además se relacionan más con el tema más «polémico» planteado por Spitzer. En la tercera de sus cinco conferencias de 1937 en la Universidad Johns Hopkins, titulada «La idealización de la realidad (Garcilaso de la Vega)», que con las demás fue recogida en La realidad y el poeta, 1940, define la obra del poeta renacentista como «La poesía de la ilusión o figuración de la realidad. Aquella que inventa un mundo imaginario, un disfraz de lo real, de modo que parezca ilusión, hermosura. Es la salvación de lo real por la vía del embellecerlo convirtiéndolo en ilusión» (carta a Margarita Bonmatí, 20/2/1937, cit. en Escartín, 2008: 557). Al igual que Petrarca y Garcilaso, Salinas presenta una historia de amor en su proceso, en una sucesión de etapas o de instantes, a los que se puede volver la vista atrás: «Cuando me vuelvo a contemplar los años» (Petrarca, soneto 298); «Cuando me paro a contemplar mi estado» (Garcilaso, soneto I); «Ha sido, ocurrió, es verdad. / Fue en un día, fue una fecha...», Salinas, 127-128.

Es muy extensa de exponer la configuración renacentista que conlleva Garcilaso y encarna de un modo u otro Salinas, y ya Montserrat Escartín, entre otros, se ha ocupado de describir: el perfeccionamiento del hombre de Pico della Mirandola, los diálogos de amor de León Hebreo, el neoplatonismo de Ficino ${ }^{10}$, el discurso de Bembo en El Cortesano, de donde concluye Salinas que «defender este tipo de amor es una forma de mostrarse disconforme con una sociedad que consume relaciones de manera frívola, y de rebelarse ante un mundo pragmático que confunde amor y deseo» (Escartín, 2008: 560). Esta forma de amor neoplatónica es exactamente la misma en el Renacimiento y en Salinas, viva en la tradición: «Cuando el gozo derivado de abrazar y tocar materia se acabe, queda otro: la posesión de una realidad más alta, elevada a su última, impalpable categoría, las sombras, las puras y luminosas formas del espíritu» (Salinas, cit. en Escartín, 2008: 567). A esto Salinas lo llama «volverse sombra». Esta concepción superior e intelectual del amor es la «vía de perfección por la cual se asciende a la hermosura misma», en palabras del poeta; porque en la búsqueda de la verdad, como anunciaba Pico della Mirandola, a ésta no se llega sólo por el intelecto, sino por la perfección de los sentimientos. Para ello la mujer tiene que existir, para que se dé la «gineolatría», porque ella hace posible la búsqueda de la perfección. «Si falta una mujer la vida ya no tiene sentido» (Salinas, cit. en Escartín, 2008: 572). Con esto se demuestra que la amada existía, debiendo tomar cautelosamente a Spitzer, porque como dice Jorge Guillén:

\footnotetext{
${ }^{10}$ Es destacable una de sus ideas, relacionada con Salinas, donde la fantasía es capaz de grabar el rostro de la amada en su alma y sangre, y así se fija en el pensamiento del enamorado. El mismo efecto se daba en el caso de la pintura, en donde la sola visión del retrato de la amada suponía esta interiorización, pintura o impresión de la amada en el alma del enamorado. El propio Salinas conservaba varios retratos de Katherine, que contemplaba con devoción casi religiosa (Salinas, 2002: 267-268). El propio Cervantes, en el Persiles, postulaba este mismo hecho (Suárez Miramón, 2004: 1033): «[...] el ejemplo de Sinforosa para quien su amor pasó de ser pensamiento a estar grabado como "pintura en el alma"». Para mayor información de la impresión de la imagen en el amante, véase la obra de Serés (1996).
} 
«Este sentido vital se entiende y se siente sólo bien asentado y encajado en una materia concreta» (Jorge Guillén, 1967: 144).

Ahora bien, es cierto que desde el petrarquismo, o antes, desde el amor cortés provenzal, «el amor es una invención de la cultura» (Escartín, 2008: 572), con lo cual viene al caso la deducción de González Muela (1974: 21): «No creemos que, como dice Spitzer, el poeta escruta a la amada «para conocerse a sí mismo». No; eso se dará por añadidura; lo que está buscando el poeta es el poema [...]». Por tanto, hay dos verdades antagónicas pero complementarias: el poeta busca el poema, para lo cual podría «inventarse» a la amada, pero sin amada «real» no hay posibilidad de poema. La poesía es un fin en sí misma. Pero además, simultáneamente, en el conceptismo interior, en la intelectualización de la amada, el poeta asciende a la perfección y «se conoce a sí mismo». Esa búsqueda la abre la mujer y «Por dicho motivo, ambos poetas [Garcilaso y Salinas] sienten la misma deuda hacia la amada y le ofrecen: «la voz a ti debida ${ }^{I l}$ » (Escartín, 2008: 573). Amor, búsqueda de perfección y poesía son una tríada indisoluble.

En cuanto a por qué la voz: al igual que el poeta prefiere las partes duras del cuerpo de la amada («La frente es más segura...», 1884), la voz llega más hondo que lo que se ve con los ojos. Esta idea cobra auge en el Barroco, definido por concebir la realidad como «engañosa a los ojos»; momento en que Cervantes, con el Persiles, haciendo hincapié en la importancia de la voz ${ }^{12}$, mantuvo la general concepción de ésta como medio de expresión del alma. Se observa entonces la siguiente correlación, entre la dimensión del alma en la voz del poeta Garcilaso (9-16 Égloga III):

Y aún no se me figura que me toca

aqueste oficio solamente en vida;

mas con la lengua muerta y fría en la boca

pienso mover la voz a ti debida.

Libre mi alma de su estrecha roca

por el Estigio lago conducida,

celebrándose irá, y aquel sonido

hará parar las aguas del olvido.

...y la concepción de la voz de la amada para el poeta Salinas:

[...] Lo que más

pena me ha dado, al callártela,

es tu voz. Densa, tan cálida,

más palpable que tu cuerpo.

[...] (1957-1960)

\footnotetext{
11 Anota Escartín (2008: 573, nota 30) el bello testimonio de K. Whitmore: «[Pedro] me dijo que el nombre de "nuestro libro" sería La voz a ti debida por una égloga [la III] de Garcilaso de la Vega. La había encontrado esa mañana en edición de bolsillo: edición que tengo ahora yo encuadernada en piel blanca».

12 Cervantes otorga a la voz, en una serie de escenas, un poder mágico o encantador que despierta la atención o conmueve a los personajes. Véase Rull, Enrique (2005).
} 
[...]

Un día, al fin, hablaste,

pero tan desde el alma,

tan desde lejos,

que tu voz fue una pura

sombra de tu voz, y yo

nunca, nunca la oí.

[...] (1648-1653)

Esta forma de percibir la voz parece corresponder con la propia forma de percepción de Salinas del amor, en su lectura de Garcilaso, que es «un amor que es siempre aspiración y reminiscencia, delicado y tembloroso, como si estuviera en vilo, sin tierra en que descansar» (Ciplijauskaité, 1991: 98, [Salinas, RyP, 231]).

Escartín (1993: 147) llega a detectar la reminiscencia del Génesis («Verbo resplandeciente») en la sinestesia de referirse a la voz para ensalzar la luminosidad de la amada: «Tu voz tiene una luz que me ilumina, / luz del oír» (Razón de amor, vv. 1005-1006). Los primeros versos de este poema («Si la voz se sintiera con los ojos / ¡ay, cómo te vería!», 1003-1004) también los encuadra Escartín (2016-297) en la tradición, al relacionarlos con Quevedo: «Si mis párpados, Lisi, labios fueran». Este tópico de la voz también encuentra ecos en su Poesía inédita (Escartín, 2013: 19).

\section{LAS CARTAS DE SALINAS Y LA TRADICIÓN CLÁSICA CASTELLANA}

Merece atención muy especial la obra publicada en 2002 por Enric Bou a la que ya nos hemos referido anteriormente, Cartas a Katherine Whitmore. Las cartas tienen su gestación en el campo de cultivo de la tradición poética y en la experiencia real, amorosa, del poeta, por lo que resultan de interés primordial para el análisis y comprensión de la gestación de La voz a ti debida. Además, Claudio Guillén y el propio Salinas (Defensa de la carta misiva, 2007b: 849-917) han demostrado que el género epistolar goza de notable literariedad (Peragón, 2004: 467). Sin embargo no debemos caer en el error de buscar toda explicación poética en la parte biográfica, por lo que comenta Luis Antonio de Villena (2002):

Por supuesto que La voz a ti debida y Razón de amor van más lejos que la historia concreta que los movió en realidad. Pero sin esa historia (sin Katherine Whitmore) no hubieran existido. Y las cartas lo exhiben sin cesar. Cartas literarias e íntimas donde no sólo entendemos mejor a Salinas, sino que nos muestran —otra vez — cómo literatura y vida, que no coinciden, continuamente se interpenetran.

La relación amorosa, que fue mayoritariamente a distancia, nació y vivió por escrito, concentrada en las cartas. Al mismo tiempo, La voz a ti debida y Razón de amor nacieron en esas mismas cartas. La distancia, y a causa de ella, el fenómeno que se produce entre la experiencia vivida y la experiencia sentida, o entre realidad y pensamiento, es el germen de 
la obra poética y de su inseparable amor real. No debe olvidarse que la distancia es espacio-temporal, no sólo espacial. El recuerdo de un momento vivido intensamente se agiganta y se revive en el pensamiento.

Este hecho está íntimamente relacionado con lo ya expuesto acerca de la tradición clásica castellana, porque la poesía de amor cortés, y toda la posterior que hunde sus raíces en ella, respira en la distancia, es ésta su hábitat de gestación. El que se trate de un amor inalcanzable tiene un vínculo directo con la distancia y el pensamiento, mientras que amores de otro tipo, digamos los «asequibles», producen otro tipo de poesía, la rama alegre de la lírica popular, por ejemplo, o las serranillas. Recordemos que para que se trate de amor cortés tienen que cumplirse los cuatro rasgos de C. S. Lewis. De este amor, «invención de la cultura medieval», procede la posterior poesía petrarquista y garcilasiana basada en la ya estudiada figuración de la realidad por Escartín Gual (2008: 557) o el hiperbólico «conceptismo interior» propuesto por Spitzer (1941).

El ejercicio epistolar conlleva, por tanto, la génesis de la estructura de la dualidad amor-poesía. Esto ocurre porque no se puede escribir con la debida fuerza ilocutiva sin la recepción y la retroalimentación de alguien concreto, ya sea una persona o un colectivo, a quien va dirigida la obra. Si es de amor de lo que se escribe, es necesaria esa correspondencia, como ocurre ya no sólo al escribir, sino al amar. Hace falta que se nos devuelva el reflejo, como la luz de la luna, «a modo de esperanza», que diría Valente, o de «futuro, [...] de amor contenido y vuelto hacia el mañana» que experimentó Salinas (2002: 268). Así, esa retroalimentación buscada mediante el acto epistolar, el mensaje, es descubierta por Salinas, que denomina «Teoría Alicante-amor, 1935» (2002: 270-271):

Era un acto de amor incompleto, aún. Al recibirlo con tu alma, ya me he expresado. Eso es lo hermoso, y lo peligroso, del amor: que la consumación y realización plena de nuestros actos no dependen de uno mismo, sino del otro, también. Si tú no leyeras mis cartas con atención de alma, hasta el fondo, $m i$ amor, no el nuestro, no, el mío, se quedaría imperfecto, y lo que yo he pensado y sentido aquí, por hermoso que pudiera ser, en sí, no alcanzaría verdadera realidad. Llamamos cartas a esto, pero son mucho más. Si un día tú o yo dejáramos de leer las cartas (operación del alma que incluye cosas harto más delicadas y profundas de lo que dicen estas palabras) con todo nuestro fervor, mal le iría a nuestro amor.

Ahí se explica a la perfección la importancia esencial del destinatario para la realización del amor y, por tanto, de la poesía amorosa. Se puede inducir que toda la lírica de la tradición clásica castellana se funda en la lectura por parte del destinatario, lo que lleva a concebir, por un momento, la obra poética como mensaje. Esto no puede dudarse en Salinas, puesto que buena parte de $L a$ voz proviene de la previa redacción epistolar. Bou (2002), en sus anotaciones, aporta multitud de ejemplos. Pero, ¿no es una obra de arte algo más que un mensaje? Las cartas y las poesías eran para Katherine. Pero, al mismo tiempo, expresaba sentimientos universales, a través de su experiencia y su interiorizada tradición poética, que acarrean, por su universalidad y calidad, el imperativo de ser para el mundo. Esta es la razón por la que podemos decir que Katherine es el mundo. Pedro supo aunar en ella al receptor individual y al universal, por lo cual en sus Cartas se sigue comprobando la relación entre la tradición literaria incardinada en el lenguaje escrito y los valores humanos universales que en ella se vehiculan. 
De modo que, al entrar en juego lo universal, don Pedro ya concebía la posibilidad de que sus cartas, algún día, podrían ver la luz, como afirma Peragón (2004: 467). Salinas, en su Defensa de la carta misiva, argumenta (la citada autora nos aporta el fragmento literal en la página 468) que el hecho de comunicarse con otra persona por escrito conlleva tener que servirse del lenguaje, lo que puede deslizarse fuera de lo privado, sin que el autor lo advierta, para llegar a la intención literaria. «Porque el lenguaje tiene sus misteriosas leyes de hermosura, sus secretas exigencias, también, que tira del que escribe.» Esa tracción del lenguaje conduce inexorablemente a lo público, expulsada ya la obra del paraíso de lo privado. También aquí puede inducirse que los poetas amorosos de la tradición castellana, previos a Salinas, pasaron por esta fase.

Así, el gran legado que localizó Marichal, la universalización de los valores humanos inscritos en la tradición clásica castellana, gozaron de otro foco de difusión aquí, en las cartas, gracias a Katherine. Estos valores universales, tan propios de la cultura española y de nuestra literatura, encarnados en Salinas, reflejan, en síntesis, la imagen del amor en nuestro mundo, que Bou (Salinas, 2002: 28) expone citando a Octavio Paz, La llama doble. Los tres elementos del amor en nuestra cultura occidental son: «[...] la exclusividad, es decir, el amor hacia una sola persona (y su resultante, los celos); la atracción, que es la aceptación libre de nuestro destino; y la persona, alma y cuerpo». Todo ello se desarrolla y se consuma en las Cartas y en la trilogía amorosa La voz a ti debida, Razón de amor y Largo lamento.

Ponemos énfasis en que el verdadero germen del amor, en la tradición literaria castellana, hispánica y universal, es la ausencia. Amor y ausencia se abrazan para dar lugar al estado de amante en el amor cortés, o la postura amorosa neoplatónica en el Renacimiento, que acarrearán, por consiguiente, la obra literaria, sea epístola o poesía. La idealización que ineluctablemente se desprende del pensamiento hacia la amada es a la vez el lazo que salva esa distancia (Salinas, 2002: 63; Peragón, 2004: 472):

Sumirme más y más en la contemplación interior de lo que me falta ante los sentidos. Suplir, reemplazar la forma que no veo, el ser que no tengo, por la forma ideal que pienso, por el ser ideal que quiero.

No deja de confirmarse, por tanto, gracias al testimonio de las cartas, el tradicional estado de amante literario del que el propio Salinas habló en Jorge Manrique: tradición y originalidad, y los valores que de él se desprenden. El amor «no es un espejo de deformación, [...] sino de elevación (carta 92, 2002: 208), lo que lo acerca a la tradición mística; «Eres pura, leal, clara. De ti sólo puede venir luz alta, luz de paraíso» (carta 1, 2002: 42), lo que coincide con la gineolatría; «Te quiero tanto porque eres un alma grande, un alma bella» (carta 55, 2002: 130), que incita al poeta al perfeccionamiento de su ser, también como elevación, forzosamente compartida con la amada que alienta ese amor. No hay que olvidar que este amor no era unidireccional: Katherine también estaba enamorada de Pedro, hasta su matrimonio con Brewer.

\section{CONCLUSIONES}

Esencialmente, el entendimiento interior del amor a través de la poesía no viene de ciertos poetas anteriores, sino que viene de todos, y de todos los seres humanos que lo han experimentado en su propia piel. Se podría argumentar que la expresión poética del amor no 
ha dicho nada nuevo desde la Edad Media, y en cierto modo es así. La expresión amorosa ha dado giros, se ha enriquecido, se ha ido nutriendo diacrónicamente de todo texto previo, criándose y creciendo en su habitación que decía Salinas, siguiendo el curso de la tradición.

Todos los poetas que escribieron alentados por el amor perseguían objetivos similares, más allá de la fama, las riquezas o el favor de la dama: el poema es un pretexto para intentar alcanzar lo que hay más allá de él, ya que la creación poética es otro de los esfuerzos de perfeccionamiento ${ }^{13}$ o elevación del amante, aunque la consecución de la obra estética sea también un fin. Aquí se encuentran ambas actitudes del poeta: la de crecer gracias a ampararse en la tradición y la de mejorarse a uno mismo a través del esfuerzo en la expresión poética. «El hombre inmerso en la tradición no sabe más; es más, porque ella, al multiplicar las posibilidades de ser, le multiplica su potencia de ser» (Salinas, 2007a: 581). El poeta ha transmitido desde su ser las sensaciones y pensamientos de su experiencia amorosa, pero ha aprendido con ellos, ha sabido, además, hacerlo de manera que todos puedan concebirlos como propios, puesto que la poesía lírica, al igual que el símbolo, responde a una función gnoseológica, un aprendizaje o incluso una revelación personal (función develadora), porque todo lo que se aprende se hace desde el interior y de manera activa, como postula el constructivismo, pero en la poesía es más hondo lo que se llega a saber, porque se apoya en las emociones ${ }^{14}$. Lo que el poeta tenía dentro lo tenemos nosotros dentro, y es, y no es, lo mismo. El sentimiento universal se entiende en cada uno de la manera particular de cada uno, pero en esencia es el mismo, como decía Machado («¿Tu verdad? No, la Verdad, y ven conmigo a buscarla»). La tradición, invisible, intangible, se encuentra ahí detrás, para continuar la obra de todos a través de nosotros. Los clásicos son la escuela total. No puede expresarse mejor que como lo dice el propio Salinas (apud Escartín, 1993: 155):

Y cuando nos toque a nosotros, en nuestra modesta tarea del mundo, la necesidad de hacer partícipes a nuestros prójimos de una idea o de un sentimiento nuestros, esos clásicos que leímos estarán detrás, a nuestra espalda, invisibles pero fieles [...], ayudándonos a encontrar la justa expresión de nuestra intimidad.

El poema tiene una razón vital que arranca de la propia alma del poeta (piénsese en el porqué del título Razón de amor, además de la alusión al poema medieval ${ }^{15}$ ). Es por eso por lo que no se ha extinguido la creación poética desde que ya «se dijo todo» en la Edad Media. No vale pensar en palabras de otros, aunque calen hondo, aunque hayan dado en el blanco de las emociones. El poeta es un buscador y debe alcanzar las revelaciones de los misterios del mundo por sí mismo. Igual sucede con el lector de poesía, para quien no debe bastar lo que

${ }^{13}$ Esta aspiración a mejora de uno mismo, que relacionamos con la actividad amatoria y la creadora de poesía, puede desprenderse de estas palabras de Salinas (2007c: 577-578): «Lo que hace hermoso al ser humano no es lo que es: en eso es hermoso el animal, siendo sólo lo que es. Pero para mí lo hermoso del hombre es su querer ser, su querer. Llámalo ambición, sueño, creación, ideal [...], pero todo es un querer ser [a Margarita, 2-1-1937].

14 El lenguaje más profundo se expresa a partir de las emociones, no de razonamientos. «Primariamente, el lenguaje no expresa pensamientos o ideas sino sentimientos o emociones (Cassirer, 2012: 48).

${ }^{15}$ En esta digresión apuntamos a significados de «razón» como «motivo», «justificación», mientras que en el s. XIII tenía el sentido de «narración», «relato». Como dice Escartín (2016: 13), «En Razón, de 1936, el poeta analiza la situación tras la ruptura [...]. De ahí el título [...] en el sentido medieval del término. El razonamiento en el tema amoroso sólo puede ser la experiencia [...]». 
le digan hermeneutas: debe buscar detrás, más allá. El propio Salinas ponía énfasis en que la literatura era para los lectores, no para los críticos (Blecua, 1988: 18).

Todo esto debe tenerse en cuenta en la observación de la poesía inmersa en la tradición, en la que uno ve los moldes, las formas en las que se apoya y con las que se ha hecho. Pero no debe fijarse únicamente en eso, sino precisamente en lo que no son tópicos: Dámaso Alonso (apud Soria Olmedo, 2006: 224), afirma que el estudio de los topoi «no toca jamás a la entraña del fenómeno poético», porque el poema sobrepasa todo acercamiento desde el exterior. El poema tiene su esencia particular, y don Dámaso, en la línea estética de Croce y Vossler, afirma que «a esa esencia no se llega por escalerillas de tópicos ni fuentes. Precisamente el nuevo poema es lo otro: lo que no había en las fuentes [...]». El propio Salinas (apud Soria Olmedo, 2006: 224) apoyaba este acercamiento vitalista:

Hay, además, debajo de todo eso un querer saber que no es el fin primordial de la poesía, sino de la ciencia. ¿Es que un alma sensible necesita saber el cómo del poema? ¿No le basta con vivir lo que es? Muy bien que cada Garcilaso tenga su Herrera, bienvenido, pero lo que más importa es que tenga sus lectores, sin anotaciones. (27 de marzo de 1951.)

Con suma habilidad ha sabido Salinas combinar tradición y originalidad, recogiéndose en ésta la esencia poética particular que «no está en las fuentes». Pero esa serie de prolongaciones originales parten de la tradición, Salinas es consciente de ello, y lo hace muy a propósito y con un objetivo muy concreto, como bien hace notar Marichal (1976: 268): «Porque, finalmente, Salinas aspiraba a hacer patentes los valores humanos de la literatura española por afán de integración universal: las grandes obras hispánicas podían así contribuir al nacimiento de una auténtica comunidad humana del espíritu.» Es decir, pretendía hacer resaltar los valores humanos de la tradición literaria española con el ánimo no de hacer ninguna propaganda ideológica española, sino todo lo contrario, volcar valores humanos de sesgo universal (radicados en la cultura española) en la cultura mundial. Y dice también Marichal (1976: 259): «Por «valores humanos» [...] entendía [...] tanto las visiones singulares del hombre propias de los grandes escritores hispánicos como su pertinencia actual para la vida del lector», trazando así un puente del pasado al presente, que es justo lo que hace, por ejemplo, con la concepción neoplatónica del amor. El aludido rasgo de la alteridad amorosa, que resonaba en la tradición amorosa hispánica, es indudablemente universal.

El ingenioso Salinas, por lo tanto, logra la consecución de múltiples objetivos en una sola obra, o más bien, la gran obra poética de su vida. Desde lo básico y material, como la reputación o la atención de su amada, hasta lo más sublime: la cognición de lo más profundo del ser a través de su interior, que radica en los valores humanos universales de la tradición clásica castellana. En la cúspide de los logros tendría que ir lo primordial para un poeta: la poesía por la poesía, el fenómeno poético, que nunca se sabe si se ha logrado del todo: «Porque también los poetas, que ponen toda su fe en acabar, en rematar hasta la perfección su poema, parece que dudan si el poema se acaba en la pura poesía» (Salinas, 1970: 74).

Por último, como recomendación del propio Salinas para el conocimiento de la tradición, señalamos un rasgo típico suyo ante la literatura hispánica, clave para apreciarla, y es, en sus palabras, el continuo «pasmo ante la maravilla del mundo». La admiración es una fuerza de generosidad vital, es lo que abre un foco de luz para la experiencia estética y su inherente proceso cognitivo-emotivo. El propio Salinas le escribía a Katherine: «[...] I feel like starting, in this 
country of associations, companies, leagues, and so on, a «Brotherhood for the restoration of the sense of wonder» (Salinas, 2002: 289). Como destaca Marichal (1976: 260): «[...] Salinas apuntaba al crítico literario y más aún al profesor de literatura su deber pedagógico: acostumbrar a admirar, a gozar realizando siempre lo más universal de una obra literaria».

\section{REFERENCIAS BIBLIOGRÁFICAS}

Blecua, José Manuel (1988), «Una charla con Pedro Salinas», Ínsula, n. ${ }^{\circ}$ 499-500, p. 18.

Bou, EnRIC (2002), prólogo y edición en Salinas, Pedro, Cartas a Katherine Whitmore. Barcelona, Tusquets.

Cassirer, Ernst (2012): Antropología filosófica. México D. F., Fondo de Cultura Económica.

Ciplijauskaité, Biruté (1991), «Pedro Salinas, siervo de amor», Revista de Occidente, n. ${ }^{\circ}$ 126, Noviembre de 1991, pp. 91-105.

CRistóbal, Vicente (2005), «Sobre el concepto de tradición clásica», en Signes Codoñer, J. (ed.), Antiquae Lectiones. Madrid, Cátedra.

Debicki, Andrew (1976), Pedro Salinas. Madrid, Taurus.

Escartín Gual, Montserrat (2016), Introducción, edición y notas en Salinas, Pedro, La voz a ti debida. Razón de amor. Largo lamento. Madrid, Cátedra.

- (2013), Introducción, edición y notas en Salinas, Pedro, Poesía inédita. Madrid, Cátedra.

- (2008), «Garcilaso de la Vega y Pedro Salinas: La voz a ti debida», Revista de literatura, vol. LXX, n. ${ }^{\circ} 140$, pp. 553-575.

- (1993), «El uso de los tópicos literarios en la obra de Pedro Salinas», en Bou, Enric y Gascón-Vera, Elena (eds.), Signo y memoria: ensayos sobre Pedro Salinas, pp. 135-157. Madrid, Pliegos.

Feal Deibe, Carlos (2000), Poesía y narrativa de Pedro Salinas. Madrid, Gredos.

FERRY, LuC (2007), Aprender a vivir. Madrid, Taurus.

García de la Concha, Víctor (2000), Poetas del 27. La generación y su entorno. Antología comentada. Madrid, Espasa (Austral).

García Tejera, María del Carmen (2009), La teoría literaria de Pedro Salinas, Biblioteca Virtual Miguel de Cervantes, Alicante, edición digital a partir de la edición de Cádiz, Seminario de Teoría de la Literatura, 1988.

Garcilaso de la Vega (1995), Poesías completas. Madrid, Alianza.

GonZÁlez Muela, JoAQuín (1974), «Edición, introducción y notas», en Salinas, P., La voz a ti debida. Razón de amor. Valencia, Castalia.

Granados Palomares, Vicente (2011), Literatura española (1900-1939). Madrid, Centro de estudios Ramón Areces.

Guillén, Jorge (1967), «Pedro Salinas», MLN, Vol. 82, Núm. 2, Spanish Issue (Mar. 1967), pp. 135-148. Baltimore, The Johns Hopkins University Press.

Gullón, Ricardo (2007), «La poesía de Pedro Salinas», Biblioteca Virtual Miguel de Cervantes, Alicante. Edición digital a partir de Asomante, Año 8, núm. 2 (abril-julio 1952), pp. 32-45.

Han, Byung-Chul (2014), La agonía del Eros. Barcelona, Herder.

KATZ Krispín, Ruth (1998), «Largo lamento: el guardián de la memoria», en Sevilla Arroyo, Florencio y Alvar Ezquerra, Carlos (eds.) (2000), Actas del XIII Congreso de la Asociación Internacional de Hispanistas, Madrid, 6-11 de julio de 1998, Vol. II, pp. 662-671.

Lewis, Clive Staples (2000), La alegoría del amor. Santiago de Chile, Editorial Universitaria.

Manrique, Jorge (2013), Poesías completas. Madrid, Austral.

MARICHAL, JuAn (2002), El exilio español fue una fortuna. Madrid, Exilio.

- (1976), «Pedro Salinas y los valores humanos de la literatura hispánica», en Debicki, Andrew P., Pedro Salinas, pp. 259-268. Madrid, Taurus. 
Paz, Octavio (1993), La llama doble: amor y erotismo. Barcelona, Seix-Barral.

Peragón López, Clara Eugenia (2004), «Algunas notas sobre la proyección literaria en el epistolario de Pedro Salinas a Katherine Whitmore», Revista de literatura, LXVI, 132, pp. 465-484.

Salinas, Pedro (2016), La voz a ti debida. Razón de amor. Largo lamento. Madrid, Cátedra.

- (2013), Poesía inédita. Madrid, Cátedra.

- (2007a), Obras completas I. Poesía. Narrativa. Teatro. Madrid, Cátedra.

- (2007b), Obras completas II. Ensayos completos. Madrid, Cátedra.

- (2007c), Obras completas III. Epistolario. Madrid, Cátedra.

- (2002), Cartas a Katherine Whitmore (1932-1947). Barcelona, Tusquets.

- (1975), La poesía de Rubén Darío. Barcelona, Seix Barral.

- (1974), La voz a ti debida. Razón de amor. Valencia, Castalia.

- (1970), Jorge Manrique o tradición y originalidad. Buenos Aires. Editorial Sudamericana.

Quevedo, Francisco de (1989), Poemas escogidos. Madrid, Castalia.

Rull, EnRiQue (2005), «El encanto de la voz en el Persiles», en Pedraza Jiménez, Felipe B. y González Cañal, Rafael (eds.) (2008), Con los pies en la tierra. Don Quijote en su marco geográfico e histórico: XII Coloquio Internacional de la Asociación de Cervantistas (XII-CIAC), Argamasilla de Alba, 6-8 mayo de 2005, pp. 553-565.

SERÉs, Guillermo (1996), La transformación de los amantes. Barcelona, Crítica.

Soria Olmedo, ANdrés (2006), «Pedro Salinas: el exilio, los ensayos, las cartas», Biblioteca Virtual Miguel de Cervantes, Alicante. Edición digital a partir de 1616: Anuario de la Sociedad Española de Literatura General y Comparada, pp. 219-224.Vol. VI-VII (Año 1988).

Spitzer, Leo (1941), «El conceptismo interior de Pedro Salinas», Revista Hispánica Moderna, tomo 7, 1/1/1941, NY, Columbia University Hispanic Institute, pp. 33-70.

Suárez Miramón, ANa (2004): «Visualización teatral y alegórica en el Persiles», en Peregrinamente Peregrinos, Quinto Congreso Internacional de la Asociación de Cervantistas, Lisboa 1/5 de septiembre 2003, Alicia Villar Lecumberri (ed.), Lisboa, Asociación de Cervantistas, Fundaçao Calouste Gulbenkian, pp. 1028-1046.

VILlegas, JuAN (1976), «El amor y la salvación existencial en dos poemas de Pedro Salinas», en Debicki, Andrew P., Pedro Salinas, pp. 129-141. Madrid, Taurus.

Villena, Luis Antonio de (2002), «Cartas a Katherine Whitmore. Pedro Salinas. Ed. Enric Bou. Tusquets. Barcelona, 2002. 406 páginas, 20 euros.» Reseña en El Cultural (web). Recuperado de: http://www.elcultural.com/revista/letras/Cartas-a-Katherine-Whitmore/4765 
